\title{
Magnetic resonance imaging pre and post pulmonary vein isolation for atrial fibrillation: diagnostic accuracy to detect and characterize ablation lesions
}

\author{
Daniel A Jones ${ }^{1 *}$, Ross J Hunter ${ }^{1}$, Redha Boubertakh', Louisa Malcolme-Lawes², Prapa Kanagaratnam², \\ Nicholas S Peters ${ }^{2}$, Christoph Juli ${ }^{2}$, Victoria Baker', Mark Earley ${ }^{1}$, Simon Sporton ${ }^{1}$, Ceri Davies', Mark Westwood ${ }^{1}$, \\ Richard J Schilling ${ }^{1}$, Steffen E Petersen ${ }^{1}$
}

From 15th Annual SCMR Scientific Sessions

Orlando, FL, USA. 2-5 February 2012

\section{Summary}

LGE imaging of left atrial scar is promising and can detect pre/post ablation procedures however further quality control required to accurately depict lesion distribution

\section{Background}

We tested the hypothesis that cardiovascular magnetic resonance (CMR) imaging can reliably distinguish the presence or absence of ablation lesions by blinded analysis of pre and post ablation imaging.

\section{Methods}

Consecutive patients with paroxysmal AF in a randomised study comparing pulmonary vein isolation by wide area circumferential radiofrequency ablation (WACA) to ostial ablation with a cryo-balloon (CRYO) underwent CMR late gadolinium enhancement (LGE) imaging pre- and 3 months post ablation. Imaging was anonymized for blinded analysis of (1) LGE images, and (2) a 3D fusion image with LGE projected onto a segmented LA surface (thresholding set at 5 SD above mean ventricular signal). Scans were categorised using both assessment techniques separately as pre or post ablation, and if post ablation, whether lesions were in an ostial or WACA distribution.

${ }^{1} \mathrm{NIHR}$ Cardiovascular Biomedical Research Unit, Barts and the London NHS Trust, London, UK

Full list of author information is available at the end of the article

\section{Results}

LGE imaging was performed in 50 patients (aged $61 \pm$ 10 years, $72 \%$ male). Sensitivity and specificity for detection of ablation lesions was $60 \%$ and $96 \%$ on LGE imaging, or $88 \%$ and $82 \%$ respectively on $3 \mathrm{D}$ fusion imaging. Detection of WACA and CRYO lesion sets were correct in $14 / 24$ and $16 / 26$ respectively on LGE imaging, or $21 / 24$ and $23 / 26$ on $3 \mathrm{D}$ fusion imaging. Assessment of lesion distribution was correct for $13 / 50$ from LGE images (4/24 for WACA and 9/26 for CRYO) and $26 / 50$ from $3 \mathrm{D}$ fusion images $(\mathrm{p}=0.013 ; 13 / 24$ for WACA and $13 / 26$ for CRYO).

\section{Conclusions}

LGE imaging of atrial scar after ablation therapy is feasible. The technique still needs quality control standards established in order to determine the appropriate SD setting and to judge whether lack of peri-ostial scar is due to a sub-optimal scan or myocardial recovery

\section{Funding}

National Institute of Health Research (UK).

\section{Author details}

${ }^{1} \mathrm{NIHR}$ Cardiovascular Biomedical Research Unit, Barts and the London NHS Trust, London, UK. ${ }^{2}$ International Centre for Circulatory Health, St Marys Hospital, Imperial College Healthcare NHS Trust., London, UK.

Published: 1 February 2012 
Table 1 Diagnostic accuracy of detecting atrial scarring in blinded analysis of pre and post ablation MR images.

\begin{tabular}{ccccc}
\hline & $\begin{array}{c}\text { Sensitivity } \\
(\%)\end{array}$ & $\begin{array}{c}\text { Specificity } \\
(\%)\end{array}$ & $\begin{array}{c}\text { PPV } \\
(\%)\end{array}$ & $\begin{array}{c}\text { NPV } \\
(\%)\end{array}$ \\
\hline $\begin{array}{c}\text { Late Gadolinium } \\
\text { Enhancement }\end{array}$ & 60 & 96 & 94 & 68 \\
Segmented Fusion images & 88 & 82 & 81 & 87 \\
\hline
\end{tabular}

Table 2 Accuracy of MR images to locate atrial scarring according to ablation technique

\begin{tabular}{ccc}
\hline $\begin{array}{c}\text { Correct identification of lesion } \\
\text { distribution }\end{array}$ & LGE & $\begin{array}{c}\text { Fusion segmented } \\
\text { image }\end{array}$ \\
\hline WACA & $4 / 24$ & $13 / 24(54 \%)$ \\
Cryo & $(17 \%)$ & \\
& $9 / 26$ & $13 / 26(50 \%)$ \\
\hline
\end{tabular}

doi:10.1186/1532-429X-14-S1-P207

Cite this article as: Jones et al:: Magnetic resonance imaging pre and post pulmonary vein isolation for atrial fibrillation: diagnostic accuracy to detect and characterize ablation lesions. Journal of Cardiovascular Magnetic Resonance 2012 14(Suppl 1):P207.

Submit your next manuscript to BioMed Central and take full advantage of:

- Convenient online submission

- Thorough peer review

- No space constraints or color figure charges

- Immediate publication on acceptance

- Inclusion in PubMed, CAS, Scopus and Google Scholar

- Research which is freely available for redistribution

Submit your manuscript at www.biomedcentral.com/submit 